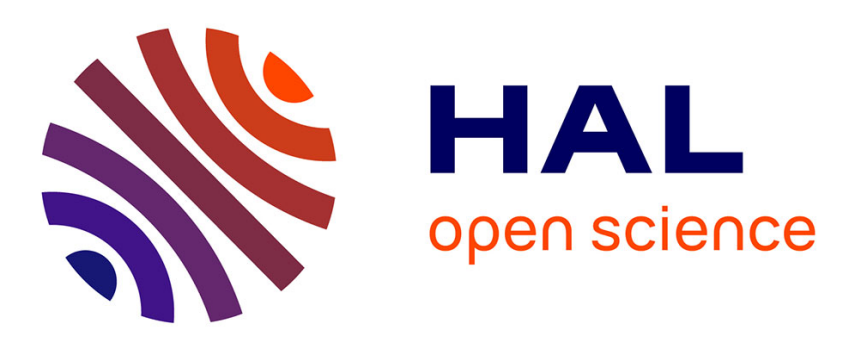

\title{
On electric field measurements in surface dielectric barrier discharge
}

S M Starikovskaia, Katia Allegraud, Olivier Guaitella, A Rousseau

\section{To cite this version:}

S M Starikovskaia, Katia Allegraud, Olivier Guaitella, A Rousseau. On electric field measurements in surface dielectric barrier discharge. Journal of Physics D: Applied Physics, 2010, 43 (12), pp.124007. 10.1088/0022-3727/43/12/124007 . hal-00569558

\section{HAL Id: hal-00569558 https://hal.science/hal-00569558}

Submitted on 25 Feb 2011

HAL is a multi-disciplinary open access archive for the deposit and dissemination of scientific research documents, whether they are published or not. The documents may come from teaching and research institutions in France or abroad, or from public or private research centers.
L'archive ouverte pluridisciplinaire HAL, est destinée au dépôt et à la diffusion de documents scientifiques de niveau recherche, publiés ou non, émanant des établissements d'enseignement et de recherche français ou étrangers, des laboratoires publics ou privés. 


\title{
On electric field measurements in surface dielectric barrier discharge.
}

\author{
S.M. Starikovskaia, K. Allegraud, O. Guaitella, A. Rousseau \\ Laboratoire de Physique des Plasmas, Ecole Polytechnique, Route de Saclay, 91128 \\ Palaiseau Cedex, France \\ E-mail: svetlana.starikovskaya@lpp.polytechnique.fr
}

\begin{abstract}
Analysis of available data on electric field measurements in surface dielectric barrier discharges (DBDs) was carried out. Experimental measurements of emission spectra in triggered and non-triggered sinusoidal surface DBD were performed. The obtained results were used for the calculation of electric field value. The comparison of data obtained and the results published by other authors is presented.
\end{abstract}




\section{Introduction}

The dielectric barrier discharge (DBD) has been extensively investigated for nearly 50 years since it is widely used for different industrial applications such as ozone production $[1,2,3]$, intensive UV-light generation [4], plasma gas and surface treatment and so on. There are two basic configurations of DBDs: volume DBD, when the discharge develops mainly in a gas gap between the electrodes, and surface DBD, when the discharge propagates along the surface. The last configuration has been studied recently for air flow control [5].

The main electrical parameters of DBDs as well as the densities of active species in the discharge and discharge afterglow have been measured and calculated for decades. Nevertheless, experimental information on electric field value in DBD microdischarges is rather limited $[6,7,8]$.

Spatially-temporally resolved nitrogen emission measurements were made in volume single-streamer DBD [6]. The authors calculated electric field in the discharge on the basis of comparison of emission of the second positive $\left(\mathrm{N}_{2}\left(\mathrm{C}^{3} \Pi_{u}\right)-\mathrm{N}_{2}\left(\mathrm{~B}^{3} \Pi_{g}\right)\right.$, $\left.\mathrm{v}^{\prime}-\mathrm{v} "=0-0, \lambda=337.1 \mathrm{~nm}\right)$ and first negative $\left(\mathrm{N}_{2}^{+}\left(\mathrm{B}^{2} \Sigma_{u}^{+}\right)-\mathrm{N}_{2}^{+}\left(\mathrm{X}_{2} \Sigma_{g}^{+}\right), \mathrm{v}^{\prime}-\mathrm{v} "=0-0\right.$, $\lambda=391.4 \mathrm{~nm}$ ) systems of molecular nitrogen. According to this data, the maximum value of reduced electric field $E / N$ is $250 \mathrm{Td}$ for sinusoidal alternating voltage, $6.5 \mathrm{kHz}$ frequency, $12 \mathrm{kV}$ peak-to-peak voltage symmetrical DBD volume discharge in synthetic air at atmospheric pressure.

The electric field in surface DBD discharge in atmospheric air along the surface of dielectric with $\varepsilon=16$ (bismuth germanate, or BGO crystal) was studied in [7]. One side of BGO crystal was covered by a transparent conductive coating and used as a grounded electrode, and another side had a dielectric mirror coating. A high voltage conical electrode was installed on the non-covered side of BGO crystal. A voltage pulse of positive polarity with a rise time of about $100 \mathrm{~ns}$, duration of more than $300 \mathrm{~ns}$ and amplitude of $10 \mathrm{kV}$ initiated the discharge. Discharge developed radially in the form of streamers propagating from the high-voltage electrode along the surface. Pockels effect, the change of polarization of the laser light passing through the crystal under the action of electric field, was used for the electric field measurements. Maximum values of the horizontal component of reduced electric field reported by authors do not exceed $100 \mathrm{Td}$ in the streamer front and $20 \mathrm{Td}$ in the channel.

Volume and surface DBDs were compared numerically in [8]. The authors [8] claim that reduced electric field in surface discharge under given conditions is not higher than 150 Td.

The surface barrier discharge in coplanar geometry (both electrodes are hidden under the layer of the dielectric) in synthetic air at atmospheric pressure was studied with the help of cross-correlation spectroscopy [9]. The authors were not able to calculate the absolute value of the electric field because of difficulties with spectral calibration, but they obtained 2D time-resolved pictures of the emission of different molecular systems. 
High values of electric field were obtained in [10], where time-resolved emission spectroscopy of molecular nitrogen was used for measurements of $E / N$ in a nanosecond surface discharge (25 ns and $20 \mathrm{kV}$ pulse) in air at different pressures, from 200 Torr to $1 \mathrm{~atm}$. The value of $780 \mathrm{Td}$ is reported for a $1 \mathrm{~atm}$ discharge of negative polarity.

Papers $[11,12]$ analyzed behavior of single streamer propagation in surface DBD configuration using fast ICCD imaging. The authors proposed to use 20-nanosecond pulse with an amplitude of $10 \%$ of peak-to-peak discharge voltage to trigger sinusoidal $50 \mathrm{~Hz}$ surface DBD at a given time moment assuming that the triggering does not change physical properties of the discharge.

The aim of the present work was (i) to analyze the electric field value in surface DBD discharge with $50 \mathrm{~Hz}$ sinusoidal power; (ii) to compare the electric field during positive and negative half-periods of the discharge; (iii) to compare the electric field in triggered and non-triggered discharges; (iv) to analyze behavior of the electric field at different distances from the high voltage electrode.

\section{Experiments}

The experiments were carried out in a $\mathrm{N}_{2}: \mathrm{O}_{2}=95: 5$ mixture to simultaneously maximize the intensity of $\mathrm{N}_{2}$ emission and avoid any uncontrolled admixtures of $\mathrm{O}_{2}$. The gases contained not more that $3 \%$ impurities. The discharge was installed in a chamber with a gas flow equal to $500 \mathrm{sccm}$. The electrode system consisted of two electrodes separated by a $4 \mathrm{~mm}$ thick glass plate. The high voltage electrode was a rectangle $2 \times 3.5 \mathrm{~cm}$ with round corners, and the grounded electrode was a $8 \times 8 \mathrm{~cm}$ square. Both electrodes were made of aluminum foil less than $0.1 \mathrm{~mm}$ thick. The high-voltage electrode was connected to a $50 \mathrm{~Hz} 20 \mathrm{kV}$ peak-to-peak sinusoidal power supply (A2E Technology). For triggered discharge (see figure 1), a nanosecond voltage pulse with a 1.5 ns rise time, 8 ns duration, and 1-2 kV amplitude (FID GmBH) has been superimposed on the sinusoidal voltage so that it was in the first quarter of period of the sinusoid. This allowed controllable initiation of the discharge at given time instant.

Discharge spectra were recorded with an Andor DH734-18U-03 iCCD camera connected to an Andor Shamrock SR303i-A spectrometer. The discharge image was focused onto the entrance slit of spectrometer with the help of UV lens. The slits were equal and were taken in the range 150-200 $\mu \mathrm{m}$, so that in the major part of the experiments the spectral slit function of the spectrometer was a triangle with a base of $0.75 \mathrm{~nm}$. Bands of molecular nitrogen were clearly identified. To determine electric field value, we measured relative intensity of the second positive $\left(\mathrm{N}_{2}\left(\mathrm{C}^{3} \Pi_{u}\right)-\right.$ $\left.\mathrm{N}_{2}\left(\mathrm{~B}^{3} \Pi_{g}\right), \mathrm{v}^{\prime}-\mathrm{v}^{\prime \prime}=0-0, \lambda=337.1 \mathrm{~nm}\right)$ and first negative $\left(\mathrm{N}_{2}^{+}\left(\mathrm{B}^{2} \Sigma_{u}^{+}\right)-\mathrm{N}_{2}^{+}\left(\mathrm{X}_{2} \Sigma_{g}^{+}\right), \mathrm{v}^{\prime}-\right.$ $\mathrm{v} "=0-0, \lambda=391.4 \mathrm{~nm})$ systems of nitrogen. The intensity distribution was integrated over the molecular bands taking into account the overlapping of the $0-0$ transition of molecular ion $(391.4 \mathrm{~nm})$ of nitrogen and of the adjacent vibrational transition of the second positive $\left(\mathrm{N}_{2}\left(\mathrm{C}^{3} \Pi_{u}\right)-\mathrm{N}_{2}\left(\mathrm{~B}^{3} \Pi_{g}\right)\right.$, v'-v" $\left.=2-5, \lambda=394.3 \mathrm{~nm}\right)$ system of molecular nitrogen. Relative calibration of spectral sensitivity of the system at 337.1 and 391.4 


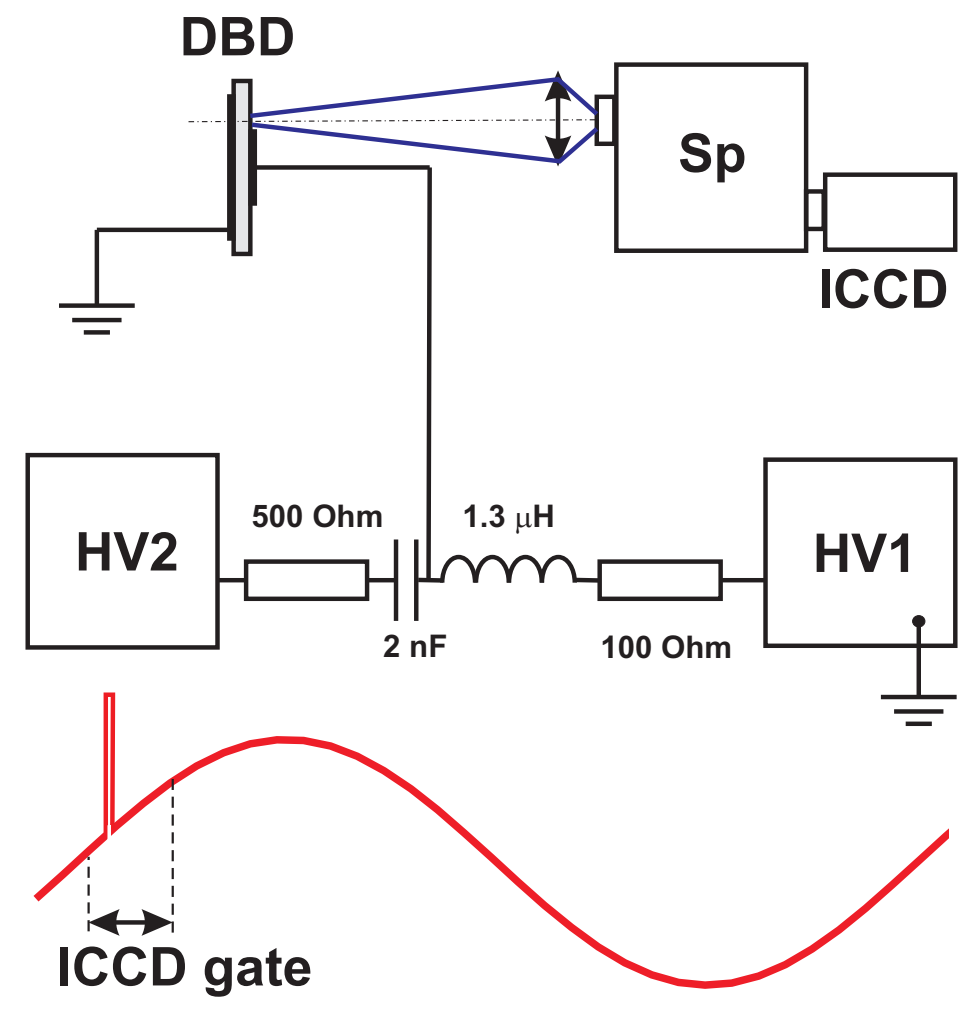

Figure 1. A schematic diagram of the experimental setup, triggered discharge: HV1, sinusoidal power supply; HV2, nanosecond pulsed power supply; DBD, discharge cell; Sp, spectrometer.

nm was made using deuterium lamp (ORIEL 63163) with known distribution of spectral intensity.

Different ICCD gates from 2 ns to $100 \mu$ s were used in the experiments. We used a 2 ns gate to get ICCD images of the discharge propagation, a $100 \mu$ s gate to get the integrated images of the discharge, and two different gates (100 ns and $2 \mathrm{~ms}$ ) to collect the emission from triggered and non-triggered discharge, respectively. To measure emission intensity at different distances from the high-voltage electrode, diaphragms $3 \mathrm{~mm}$ in width were installed sequentially along the $3.5 \mathrm{~cm}$ side of the high-voltage electrode, at a distance 1.5, 5.5, and $9.5 \mathrm{~mm}$ from the electrode. The diaphragms were made of plastic and were placed $5 \mathrm{~mm}$ above the discharge plane; a UV optical fiber installed $2.5 \mathrm{~cm}$ above the discharge plane was used to collect the emission.

\section{Approach to data treatment}

There are two different approaches to linking the intensity ratio of the two bands of nitrogen and the electric field. The first approach, theoretical, is based on knowledge of emission cross-sections for selected molecular bands. Indeed, in a quasi-steadystate approach, the rate of population by direct electronic impact is equal to the 


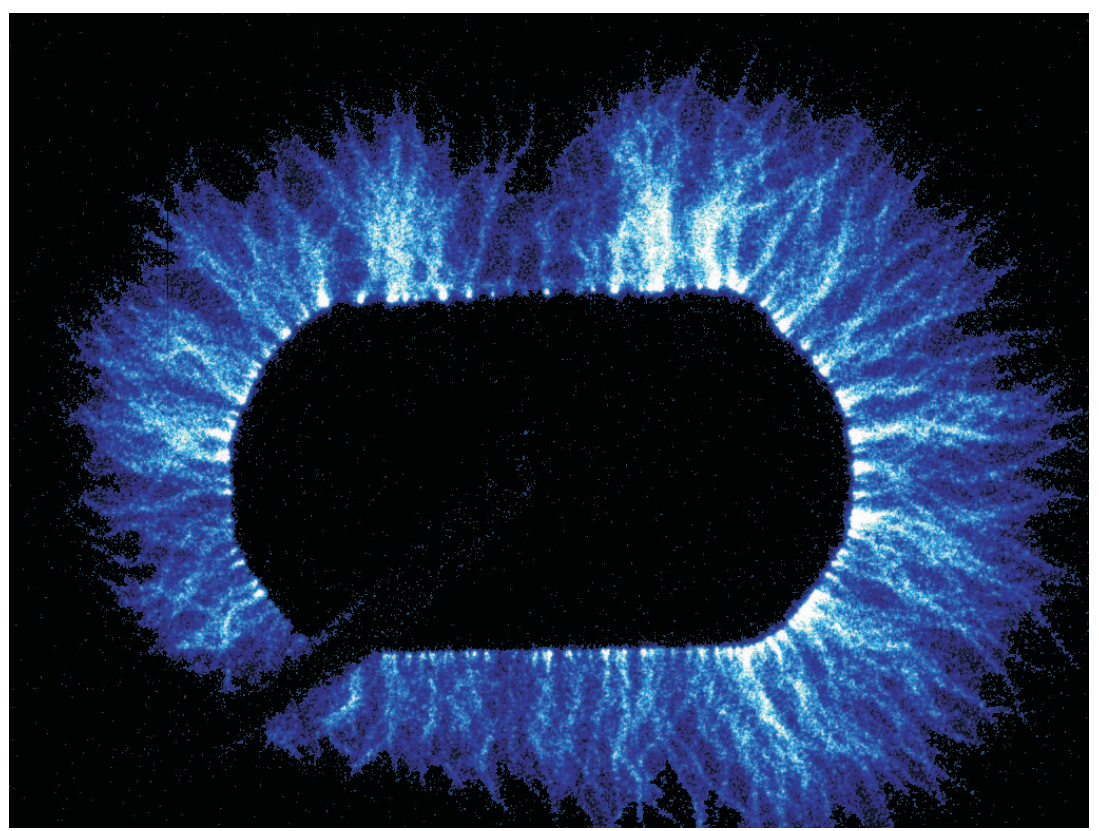

Figure 2. General view of the surface DBD for a positive applied voltage $(10 \mathrm{kV})$. ICCD gate is equal to $2 \mathrm{~ms}$.

rate of depopulation due to emission and quenching. The ratio of rate constants of excitation, $k_{\mathrm{C}} / k_{\mathrm{B}}$, depends upon ratio of population of excited levels, $\mathrm{N}_{2}\left(\mathrm{C}^{3} \Pi_{u}\right)$, v' $=0$, and $\mathrm{N}_{2}^{+}\left(\mathrm{B}^{2} \Sigma_{u}^{+}\right), \mathrm{v}^{\prime}=0$. The population of excited species and optical emission are unambiguously related to each other. On the other hand, $k_{\mathrm{C}} / k_{\mathrm{B}}$ can be calculated for the given electron energy distribution function (EEDF) using known cross-sections. More detailed description of this approach can be found in [6].

The second, experimental, approach is based on the results of paper [13], where the authors measured ratios of emission $I_{391.4} / I_{337.1}$ and $I_{391.4} / I_{394.3}$ at different wavelengths under fixed $E / N$ values in non-sustained discharge in synthetic air.

The theoretical approach described above, applied by different group of scientists, gave $E / N$ values about $40 \%$ lower than the experiments, this fact is discussed in [13]. Later, in [14], the authors of [13] recalculated their experimental data using higher values of rate constants of quenching for the molecular nitrogen ion, given by [15], and demonstrated a good coincidence between their experimental data and the results of the calculations. The authors of [14] came to the conclusion that this was the main reason of discrepancy. Finally, papers $[13,14]$ can be considered as an experimental check of the model to calculate $I_{391.4} / I_{337.1}$ dependence upon reduced electric field. It is recommended to use the rate constants given by [15] for the adequate description of quenching of the molecular ion. As far as our experiments were made in gas mixture not equivalent to air composition, we used the theoretical approach to treat the experimental data obtained in this paper.

It should be pointed out that in relating the ratio of emission of the $1^{-}$and $2^{+}$ systems of molecular nitrogen to the electric field value, we have to consider a few 
limitations and a few conditions to be fulfilled.

First, the upper states of the transitions (that is $\mathrm{N}_{2}\left(\mathrm{C}^{3} \Pi_{u}\right), \mathrm{v}^{\prime}=0$ and $\mathrm{N}_{2}^{+}\left(\mathrm{B}^{2} \Sigma_{u}^{+}\right)$, $\left.\mathrm{v}^{\prime}=0\right)$ must be populated by direct electron impact and depopulated by radiation and quenching $[16,6]$. Typically, the nanosecond discharge provides the direct population during the current pulse [16]. This can easily be checked experimentally under our conditions. The efficient lifetime of $\mathrm{N}_{2}\left(\mathrm{C}^{3} \Pi_{u}\right)$ is equal to $1.6 \mathrm{~ns}$, and the efficient life time of $\mathrm{N}_{2}^{+}\left(\mathrm{B}^{2} \Sigma_{u}^{+}\right)$is equal to $0.16 \mathrm{~ns}$ in $\mathrm{N}_{2}: \mathrm{O}_{2}=95: 5$ mixture at ambient temperature and 1 atm pressure, due to efficient quenching by molecular oxygen. This means that the temporal behavior of the emission has to be close to the shape of the electrical current. We did not measure both current and emission profile at the present work but judging from our experience of work with the discharges, we assumed this similarity.

Second, we measure time-averaged emission spectra which means that they averaged automatically over the current pulse duration. Under the conditions of our experiments, the current pulse duration did not exceed $40 \mathrm{~ns}$. This means that we discuss a certain average value of the electric field in the pulse which is probably close to the maximum value due to a high intensity of emission in the heads of the streamers propagating along the surface. In our opinion, the field increases sharply within a few ns and then decreases during tens of nanoseconds to some lower values. To analyze in detail the spatio-temporal profile of the field, emission measurements with at least $1 \mathrm{~ns}$ time resolution have to be done.

\section{Results and discussion}

It was found that both for test experiments in ambient air and for experiments in a $\mathrm{N}_{2}: \mathrm{O}_{2}=95: 5$ mixture, for triggered and non-triggered discharge, the emission of molecular $\mathrm{N}_{2}$ ion (391.4 nm) during a positive half-cycle of the discharge is significantly stronger than the emission of adjacent $\mathrm{N}_{2}$ band $(394.3 \mathrm{~nm})$. This fact, which is clearly illustrated by figure 3, proves that the electric field value in the discharge is fairly high. This result is in a good correlation with spectra presented in [17] for air flow control surface DBD experiments. It should be noted that the spectra obtained demonstrate the possibility of a relatively easy selection of the 391.4 band of molecular nitrogen ion due to its high intensity in comparison with adjacent bands of $2^{+}$system. This means that 2D mapping of the electric field in the surface dielectric barrier discharge is possible using emission spectroscopy.

In the non-triggered regime, the ICCD camera gate was equal to $2 \mathrm{~ms}$ and the camera was synchronized with the high-voltage power supply so that the discharge was registered during only a part of the positive slope of a positive half-period of the voltage. We averaged 4000 accumulations, or 4000 periods of sinusoidal voltage. During each half-period of the sinusoidal voltage about 10 discharges, each a few tens nanosecond duration, were accumulated. The time to take one spectrum was equal to $25 \mathrm{~min}$.

To calculate the electric field on the basis of theoretical considerations, we used an electron energy distribution function (EEDF) obtained on the basis of solution of 


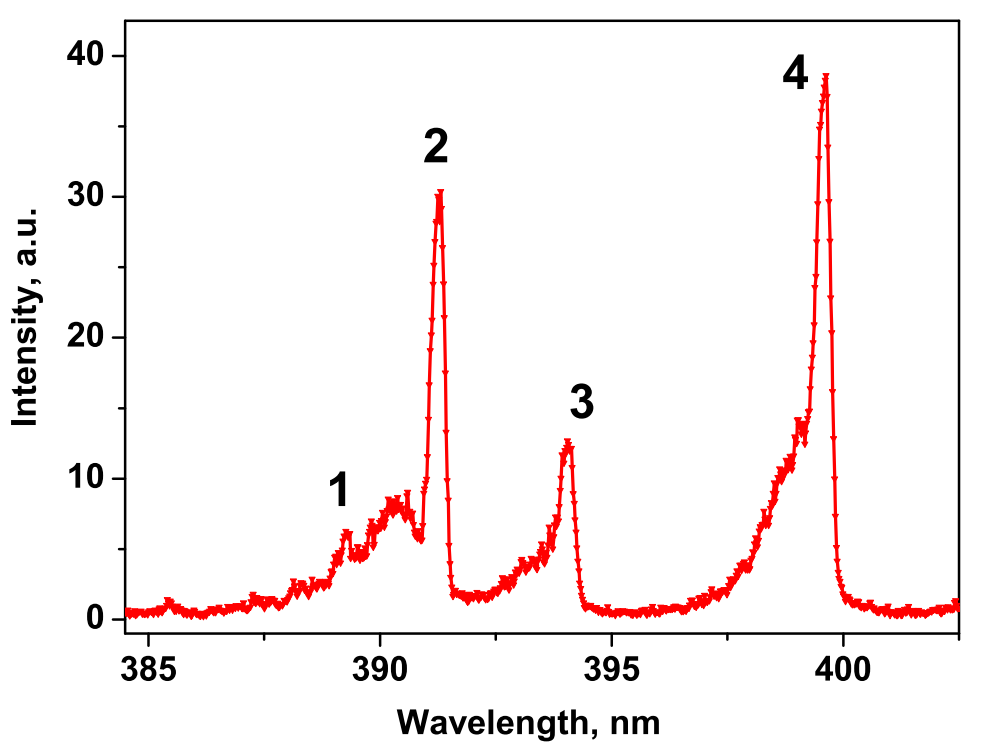

Figure 3. Emission of molecular nitrogen during the positive half period of applied voltage. $1, \mathrm{v}^{\prime}=3-\mathrm{v}^{\prime \prime}=6,2^{+}$system; $2, \mathrm{v}^{\prime}=0-\mathrm{v}^{\prime \prime}=0,1^{-}$system; $3, \mathrm{v}^{\prime}=2-\mathrm{v}^{\prime \prime}=5,2^{+}$system; $1, \mathrm{v}^{\prime}=1-\mathrm{v} "=4,2^{+}$system. Non-triggered discharge, 4000 accumulations.

Boltzmann equation in two-term approximation calculated with the help of BOLSIG+ code [18]. For electron collisions with $\mathrm{O}_{2}$ and $\mathrm{N}_{2}$, we used the self-consistent sets of cross sections available in the literature, which allow good agreement between calculations and measurements of transport and rate coefficients in pure gases $\left([19,20]\right.$ for $\mathrm{O}_{2}$ and [21] for $\mathrm{N}_{2}$ ). Emission cross-sections for appropriate transitions of the $2^{+}$and the $1^{-}$systems were taken from [22] and [23], respectively. It should be noted that this data coincides with the recommendation of review [24], and coincides with cross-sections taken in $[13,14]$ for data treatment.

Values of about $1000 \mathrm{Td}$ have been obtained for positive half-period of the discharge (see figure 4). These values are in good correlation with the results given by similar emission techniques for nanosecond surface DBD discharge [10] and differs significantly from data obtained using the Pockels effect [7]. Let us note that in general, the two-term approximation for the Boltzmann equation is invalid at high electric fields when the electron distribution is anisotropic. Nevertheless, in [14] the authors demonstrate a reasonable agreement between their experimental measurements of $I_{391.4} / I_{337.1}$ [13] in air and corresponding calculations within the range of reduced electric fields $E / N=100-1500 \mathrm{Td}$ without taking into account anisotropy of the EEDF. This fact allows us using the approach described above for calculations of the electric field without the detailed analysis of possible anisotropy.

It is known from ICCD imaging with micro- and millisecond camera gates (see, for example, [11]) that the emission of surface DBD is bright and filamentary during 


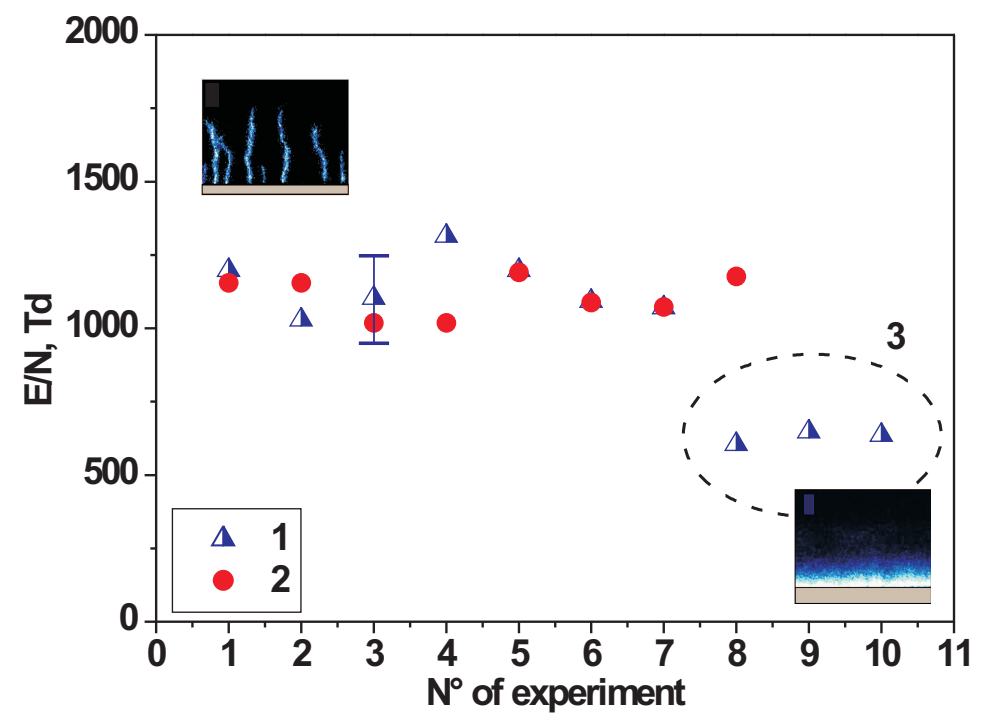

Figure 4. Reduced electric field, calculated from the ratio of intensities of emission at $391.4 \mathrm{~nm}$ and $337.1 \mathrm{~nm}$. 1, non-triggered discharge, 10-12 kV HV amplitude (exp. 1-6, $10 \mathrm{kV}$, exp. 7, $12 \mathrm{kV}$ ), positive half-period; 2, triggered discharge, $10 \mathrm{kV} \mathrm{HV}$ amplitude, positive half-period; 3, non-triggered discharge, 10-12 kV HV amplitude (exp. 8, $12 \mathrm{kV}$, exp. 9-10, $10 \mathrm{kV}$ ), negative half-period.

a positive half-period of the applied voltage, while during a negative half-period the emission is weak and more diffuse. This is illustrated by appropriate ICCD images (100 $\mu$ s camera gate) in figure 4. According to our observations, during a negative halfperiod the emission of nitrogen ion at $391.4 \mathrm{~nm}$ becomes weak in comparison with $\mathrm{N}_{2}$ emission at $394.3 \mathrm{~nm}\left(\mathrm{v}^{\prime}-\mathrm{v}^{\prime \prime}=2-5\right.$ transition of the $2^{+}$system of $\left.\mathrm{N}_{2}\right)$, and the electric field drops by a factor of nearly 2 (see figure 4 ).

To have a possibility to synchronize the discharge development and the diagnostic system, it was proposed in [12] to apply an additional HV pulse at the front of the main voltage waveform. Here, we checked the difference in emission for triggered and non-triggered sinusoidal DBDs. Let us note that for triggered discharge, only a single current peak is initiated [12] with a typical duration of $40 \mathrm{~ns}$, while for non-triggered discharge [11] 10-30 current peaks were observed, each with a duration of 10-20 ns and a typical time interval between peaks of 10-100 $\mu \mathrm{s}$. The current in a single peak in the case of triggered discharge is carried by a set of streamers starting simultaneously (within a ICCD gate of $2 \mathrm{~ns}$ ) from the high-voltage electrode.

To get a spectrum in triggered discharge, the ICCD gate was decreased to $100 \mathrm{~ns}$, so that not more than one current peak was registered during a given period. To have a reasonable signal-to-noise ratio, it was necessary to make 10000 accumulations during 1 hour. It was found (see figure 4) that the electric field values coincide in triggered and non-triggered discharge. This experimental conclusion allows planning of time-resolved 
measurements of the electric field behavior.

Dependence of the electric field upon distance from the high-voltage electrode was measured during a positive half-period of the non-triggered discharge. The ICCD camera gate was equal to $2 \mathrm{~ms}, 20000$ accumulations were used, and the time to take one spectrum was equal to 2 hours. In order to check the stability of the discharge, spectra were taken in two directions, from 320 to $405 \mathrm{~nm}$, and then immediately from $405 \mathrm{~nm}$ to $320 \mathrm{~nm}$. No difference was found between the spectra and no deterioration of the glass surface was observed. It was concluded that at different distances from the high-voltage electrode, $1.5,5.5$, and $9.5 \mathrm{~mm}$, the emission intensity drops significantly while the electric field value remains practically constant (see figure 5). Let us note that the error bar here is mainly connected to possible limits of integration of the noisy emission signal at $391.4 \mathrm{~nm}$.

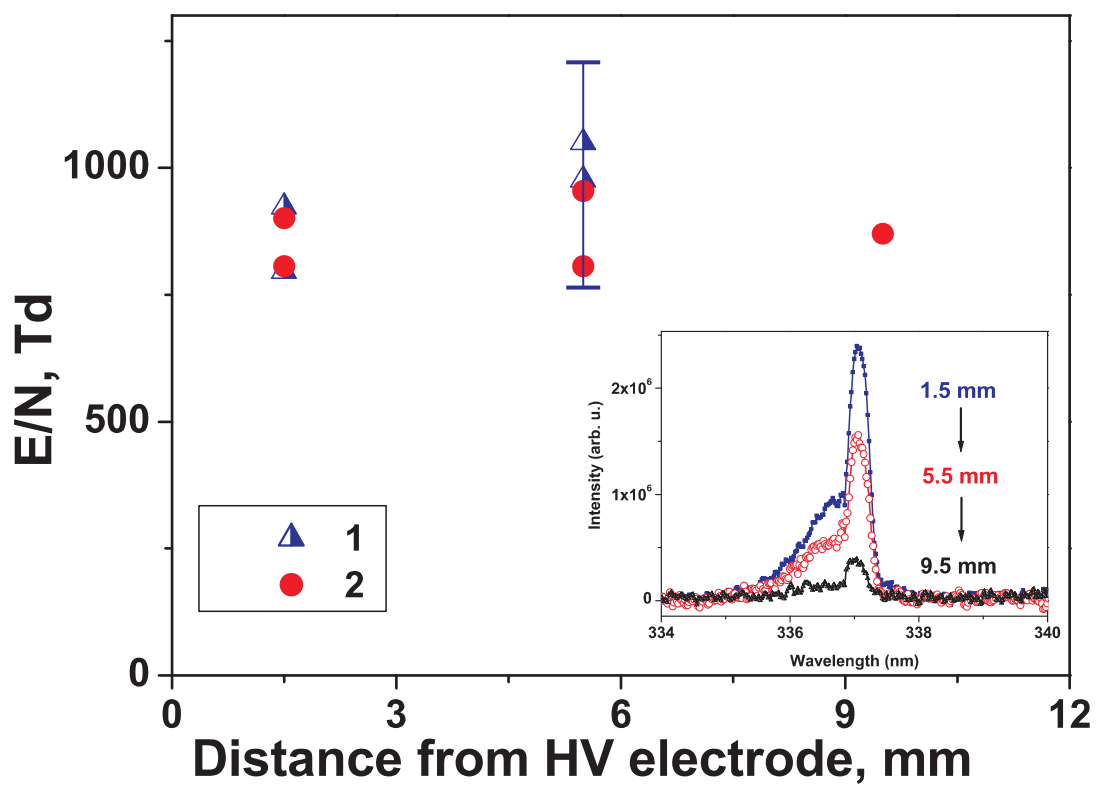

Figure 5. Reduced electric field, different distances from the high voltage electrode, non-triggered discharge. 1, $10 \mathrm{kV} \mathrm{HV}$ amplitude; 2, $12 \mathrm{kV} \mathrm{HV}$ amplitude. The insert illustrates the decrease of the emission with distance from the HV electrode.

Finally, it is interesting to qualitatively compare ICCD images obtained with short ICCD gates (1 and $0.2 \mathrm{~ns}$ ) for a sinusoidal $50 \mathrm{~Hz}$ dielectric barrier discharge with glass dielectric [12] and for a 25-ns surface DBD discharge with a PVC dielectric [25] in air at 1 atm (see figure 6). Similar results for nanosecond surface barrier discharge in a linear geometry of electrodes were obtained earlier for teflon and kapton as a dielectric at the same laboratory [10]. As the camera's spectral response is $200-800 \mathrm{~nm}$, both experiments $[12,25]$ primarily collected emission of the second positive system of molecular nitrogen. At atmospheric pressure, quenching by molecular oxygen is strong and thus 0.2-2 ns gates give an "instantaneous" picture of the discharge development. Let us note that in spite of the similar values of the electric fields, the morphology of the discharges seems to be rather different: the $50 \mathrm{~Hz}$ discharge demonstrates bright emission 

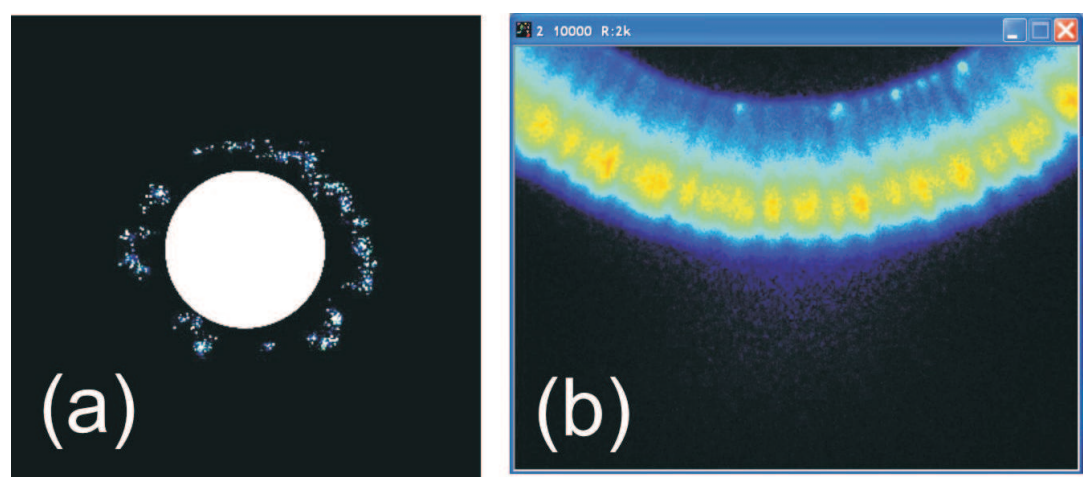

Figure 6. ICCD images of (a) triggered surface DBD discharge, camera gate is 2 ns, and (b) nanosecond surface barrier discharge, camera gate is 0.2 ns [25].

from the "streamer heads" similar to development of a streamer discharge in $1 \mathrm{~atm}$ air gap, while the nanosecond surface discharge exhibits strong emission of molecular nitrogen both from the "streamer heads" and from the "channels", demonstrating a presence of high electric fields behind the discharge front. We believe that comparative analysis of spatio-temporal behavior of the electric field in these two discharges will be of a great interest.

\section{Conclusions}

Thus, experimental measurements of emission of molecular nitrogen have been performed for $50 \mathrm{~Hz} 20 \mathrm{kV}$ peak-to-peak surface DBD discharge and for the same discharge in the case when microdischarges are triggered by an external nanosecond pulse of $1-2 \mathrm{kV}$ in amplitude. It was demonstrated that the discharge allows the accumulation of the emission signal without change of the parameters of the discharge for at least 2 hours.

It was found that the electric field values in surface DBDs can be as high as 700-1100 Td. It was determined on the basis of spectral measurements that triggering by a short nanosecond pulse with the amplitude of $10 \%$ of maximum voltage on the HV electrode does not change the electric field. This fact opens a possibility to perform time- and space-resolved emission measurements and to verify available numerical calculations of the electric field behavior in surface DBDs. With propagation from the HV electrode, the emission intensity decreases while the electric field remains practically constant.

\section{Acknowledgements}

This work was partially supported by ANR (RAMPE Project) and EOARD AFOSR, grant FA8655-09-1-3077. The authors are thankful to Dr. P.Paris (Institute of Physics, University of Tartu) and Dr. K.V.Kozlov (Moscow State University) for fruitful discussions concerning data treatment. 
[1] Filippov Yu V 1959 Vestnik MGU, Seria Khimia 4153

[2] Eliasson B, Hirth M, and Kogelschatz U 1987 J. Phys. D: Appl. Phys. 201421

[3] Samoilovich V G, Gibalov V I, Kozlov K V 1989 Physical Chemistry of Barrier Discharge (Moscow: Moscow State University Publ., in Russian) pp 1-176

[4] Borisov V M, Vodchits V A, Eltsov A V, Christophorov O B 1998 Quantum electronics 25308

[5] Roth J R, Sherman D M, Wilkinson S P 2000 AIAA Jounal bf 381166

[6] Kozlov K V, Wagner H-E, Brandenburg R, and Michel P 2001 J. Phys. D: Appl. Phys. 343164

[7] Tanaka D, Matsuoka S, Kumada A, and Hidaka K 2009 J. Phys. D: Appl. Phys. 42075204 (6pp)

[8] Gibalov V I and Pietsch G J 2000 J. Phys. D: Appl. Phys. 332618

[9] Hoder T, Sira M, Kozlov K V, Wagner H-E 2008 J. Phys. D: Appl. Phys. 41035212 (9pp)

[10] Roupassov D V, Nikipelov A A, Nudnova M M, Starikovskii A Yu 2009 AIAA Journal 47, 168

[11] Allegraud K, Guaitella O, and Rousseau A 2007 J. Phys. D: Appl. Phys. 407698

[12] Allegraud K, Rousseau A 2008 IEEE Trans. on Dielectrics and Electrical Insulation 16435

[13] Paris P, Aints M, Valk F, Plank T, Haljaste A, Kozlov K V, and Wagner H-E 2005 J. Phys. D: Appl. Phys. 383894

[14] Paris P, Aints M, Valk F 2009 Book of Contributed Papers, 17th Symposium on Application of Plasma Processes and Visegrad Workshop on Research of Plasma Physics (Liptovsky Jan, Slovakia, 17-22 January) p 227

[15] Pancheshnyi S V, Starikovskaia S M, Starikovskii A Yu 2000 Chemical Physics 262349

[16] Pancheshnyi S V, Starikovskaia S M, Starikovskii A Yu 1999 J. Phys. D: Appl. Phys. 322219

[17] B.Dong, PhD Thesis, 2008, GREMI, Orleans, France.

[18] Hagelaar G J M, Pitchford L C 2005 Plasma Sources Sci. Technol. 14722

[19] Braginskiy O V, Vasilieva A N, Klopovskiy K S, Kovalev A S, Lopaev D V, Proshina O V, Rakhimova T V, Rakhimov A T 2005 J. Phys. D: Appl. Phys. 383609

[20] Ionin A A, Kochetov I V, Napartovich A P, Yuryshev N N 2007 J. Phys. D: Appl. Phys. 4025

[21] Phelps A V and Pitchford L C, JILA Information Center Report No. 26, University of Colorado (May 1, 1985); 1985 Phys. Rev. A 312932

[22] Skubenich V V, Zapesochnyi I P 1975 High Energy Chem 9 387, in Russian.

[23] Borst W L and Zipf E C 1970 Phys. Rev. A 1834

[24] Itikawa Yu 2006 J. Phys. Chem. Ref. Data 3531

[25] Kosarev I N, Sagulenko P N, Khorunzhenko V I, Starikovskaia S M, Proc. of 19th International Symposium on Plasma Chemistry, Bochum, Germany, July 26th - 31st, 2009. 